\title{
Ankylosing spondylitis and spinal cord injury: origin, incidence, management, and avoidance
}

\author{
W. Bradley Jacobs, M.D., And Michael G. Fehlings, M.D., Ph.D., F.R.C.S.C. \\ Department of Surgery, Division of Neurosurgery, Toronto Western Hospital, \\ University Health Network, University of Toronto, Ontario, Canada
}

\begin{abstract}
$\checkmark$ Ankylosing spondylitis (AS) is a chronic inflammatory rheumatic disease that primarily affects the vertebral column and sacroiliac joints. Over time, the disease process promotes extensive remodeling of the spinal axis via ligamentous ossification, vertebral joint fusion, osteoporosis, and kyphosis. These pathological changes result in a weakened vertebral column with increased susceptibility to fractures and spinal cord injury (SCI). Spinal cord injury is often exacerbated by the highly unstable nature of vertebral column fractures in AS. A high incidence of missed fractures in the ankylosed spine as well as an increased incidence of spinal epidural hematoma also worsens the severity of SCI. Spinal cord injury in AS is a complex problem associated with high morbidity and mortality rates, which can be attributed to the severity of the injury, associated medical comorbidities, and the advanced age of most patients with AS who suffer an SCI. In this paper the authors outline the factors that increase the incidence of vertebral column fractures and SCI in AS and discuss the management of SCI in patients with AS. Primary prevention strategies for SCI in patients with AS are outlined as well. (DOI: 10.3171/FOC/2008/24/1/E12)
\end{abstract}

\section{KEY WORDS • ankylosing spondylitis epidural hematoma}

A NKYLOSING spondylitis is the major subtype of an interrelated group of seronegative rheumatic spondyloarthritides that also includes psoriatic spondyloarthritis, reactive spondyloarthritis, spondyloarthritis associated with inflammatory bowel disease, and undifferentiated spondyloarthritis. ${ }^{10}$ Ankylosing spondylitis primarily affects the axial skeleton (sacroiliac joints and spinal column) and is a chronic lifelong disease that often starts in young adults, with the age at onset being $<30$ years in $80 \%$ of patients. ${ }^{18}$ The usual disease pattern is one of slow and steady progression, and as such, complications of AS, such as spinal fractures, are not frequently manifested until much later in life. The incidence of AS is between 0.5 and 14 per 100,000 people per year, whereas the prevalence is between 0.1 and $1.4 \% .{ }^{9}$ Men are affected approximately twice as often as women. ${ }^{18}$

The seronegative spondyloarthropathies have a genetic predisposition related to the major histocompatibility complex Class I molecule HLA-B27. Ninety to $95 \%$ of patients with AS are positive for HLA-B27, but AS develops in only 5\% of HLA-B27-positive individuals. ${ }^{11,41}$ This finding suggests that other, as yet unidentified, genetic and environmental factors also play a significant role in the pathogenesis of AS.

The diagnosis of AS is made on the basis of both radi-

Abbreviations used in this paper: AS = ankylosing spondylitis; $\mathrm{CT}=$ computed tomography; HLA = human leukocyte antigen; $\mathrm{MR}=$ magnetic resonance; $\mathrm{SCI}=$ spinal cord injury. ographic and clinical factors known as the modified New York criteria (Table 1) ${ }^{40}$ Central to the diagnosis is the presence of sacroiliitis, as defined on radiography or MR imaging. The degree of sacroiliitis is graded from 0 to 4 , with the grade corresponding to radiographically demonstrated normal joints, suspicious changes, minor changes, moderate changes, and ankylosis, respectively. Inflammatory back pain is the central clinical feature of AS. In a controlled study Rudwaleit and colleagues ${ }^{35}$ developed diagnostic criteria to help delineate inflammatory back pain as occurs in $\mathrm{AS}$ and other spondyloarthritides from other types of back pain. The fulfillment of any 2 of their 4 criteria suggests a diagnosis of inflammatory back pain: 1) morning stiffness lasting more than 30 minutes; 2) improvement of back pain with activity and not rest; 3) awakening due to back pain during the second half of the night; and 4) alternating buttock pain.

In addition to inflammation in the axial skeleton, peripheral arthritis, enthesitis, and anterior uveitis can occur in AS. Manifestations in other organ systems, such as the pulmonary, cardiovascular, or renal systems, are rare but do occur; when present, they can have significant repercussions on the health status of the patient with AS.

\section{Vertebral Column Remodeling in AS}

The two central features of AS that promote the pathological remodeling of the vertebral column are inflammation and new bone formation. The inflammation of AS is 
TABLE 1

Modified New York criteria for AS*

\begin{tabular}{ll}
\hline \multicolumn{1}{c}{ Criteria } & \multicolumn{1}{c}{ Description } \\
\hline clinical & $\begin{array}{l}\text { inflammatory back pain } \dagger \\
\text { restriction of motion of the lumbar spine in both the } \\
\text { sagittal \& coronal planes } \\
\text { restriction of chest expansion relative to normal values } \\
\text { correlated for age \& sex } \\
\text { radiological }\end{array}$ \\
\hline
\end{tabular}

* Definite AS is present if the radiological criterion is associated with at least one clinical criterion.

$\dagger$ As defined by Rudwaleit et el., 2006.

characterized by enthesopathy, or inflammation of ligamentous insertion points, throughout the axial skeleton. This inflammatory process promotes ectopic bone formation within the affected ligaments. The widespread enthesopathy of chronic AS thus results in ossification of the ligaments of the spinal column and within the intervertebral discs, endplates, and apophyseal structures. This extensive ectopic bone formation leads to the formation of syndesmophytes, which span the ossified nucleus pulposus at each intervertebral disc level. Through the disease process, remodeling of the vertebral body also occurs. Square vertebral bodies form as a result of acute and chronic spondylitis, with destruction and rebuilding of their cortex and spongiosa. ${ }^{6}$ Accordingly, advanced AS, with its universal syndesmophytosis and squared vertebral bodies, leads to the formation of the characteristic hyperkyphotic "bamboo spine."

Although new bone formation is central to the pathogenesis of AS, this pathological entity is also associated with osteoporosis and low bone mineral density (Fig. 1). 21,26,43 This seemingly paradoxical finding is attributed to an uncoupling of the bone formation and bone resorption processes. Therefore, although ectopic bone formation occurs within the inflamed vertebral enthesis, bone resorption, through increased osteoclast activity, also occurs at an unregulated rate within the vertebra and promotes weakening of the spinal column. ${ }^{21}$

\section{Ankylosing Spondylitis Increases the Risk of Vertebral Fracture}

As the spine in the patient with AS fuses through ligamentous ossification and syndesmophytosis, a rigid hyperkyphotic deformity develops. Biomechanically, the fused spine is more akin to a long bone and acts as a rigid lever that is incapable of appropriately dissipating the energy of a traumatic event. These altered spinal biomechanics combined with the brittle quality of the osteoporotic bone in patients with AS greatly increase susceptibility to vertebral column factures, even after minor, often trivial, trauma. ${ }^{1,14,31,34}$

To further increase susceptibility to spinal fractures, the majority of patients with AS have significantly impaired mobility directly related to their rigid, kyphotic spinal deformity as well as a variable degree of peripheral joint arthritis. These factors exacerbate gait unsteadiness and thus increase susceptibility to falls. This finding has been supported in numerous case series of AS-related vertebral frac-

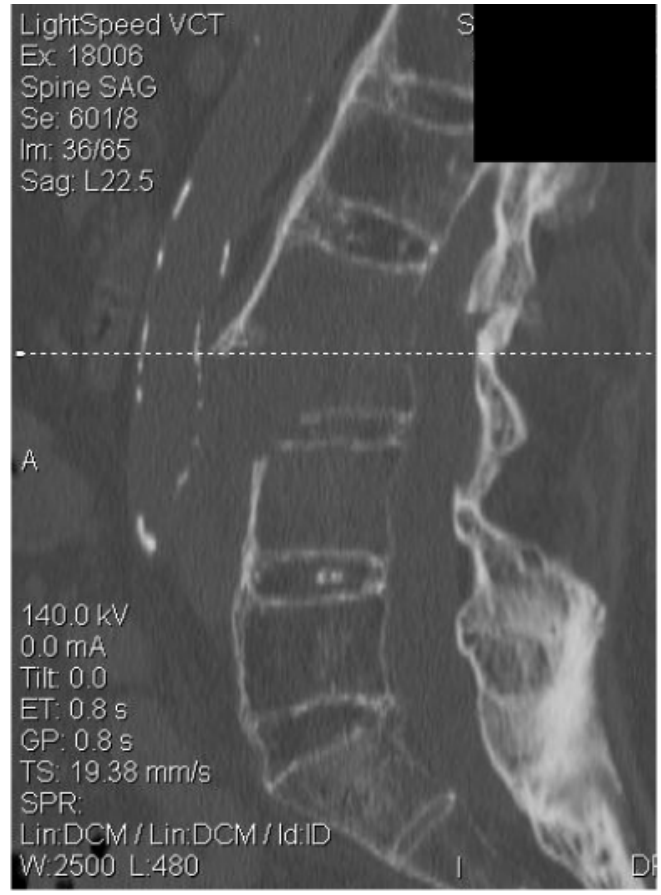

FIG. 1. Sagittal reformatted CT scan demonstrating a lumbar spine fracture in a patient with AS. Note the severe vertebral osteoporosis.

tures, when falls are almost invariably the most common

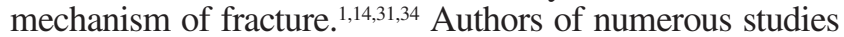
have evaluated the risk factors associated with vertebral fractures in the population with AS (reviewed by Geusens et al. ${ }^{21}$ ), and these factors include sex (men more than women), age, low body mass index, osteoporosis, disease duration, degree of syndesmophyte formation, peripheral joint involvement, increased restriction of spinal movement, and increased occiput-to-wall distance (as a surrogate measure of kyphosis). In a large review of vertebral fractures in patients with AS, Cooper et al. ${ }^{14}$ found an odds ratio of 7.7 for clinically significant vertebral column fractures, as compared with the rate in the general population. They further noted that the cumulative incidence of vertebral fractures appears to peak at $17 \%$ in the third decade after diagnosis.

Hyperextension was the most frequently observed mechanism of injury in a series of AS-related vertebral fractures, $, 1,19,20,30,39$ although the author of one series noted that flexion mechanisms predominated in a cohort. ${ }^{34}$ The prevalence of hyperextension injuries likely reflects the vulnerability of patients with AS to falls because of progressive kyphotic angulation and an inability to properly visualize the ground ahead while walking. ${ }^{34}$ Fracture patterns are also altered in patients with AS. Because of the extensive ankylosis and syndesmophyte formation, fractures often extend through the disc space and usually involve both the anterior and posterior elements of the vertebra, thus making them highly unstable (Fig. 2).

\section{AS and SCI: Incidence and Origin}

Retrospective case series of SCIs in patients with AS suggest that $1.5-2.0 \%$ of patients with such injuries also have AS,,$^{1,34,39}$ an AS prevalence that is much higher than in 


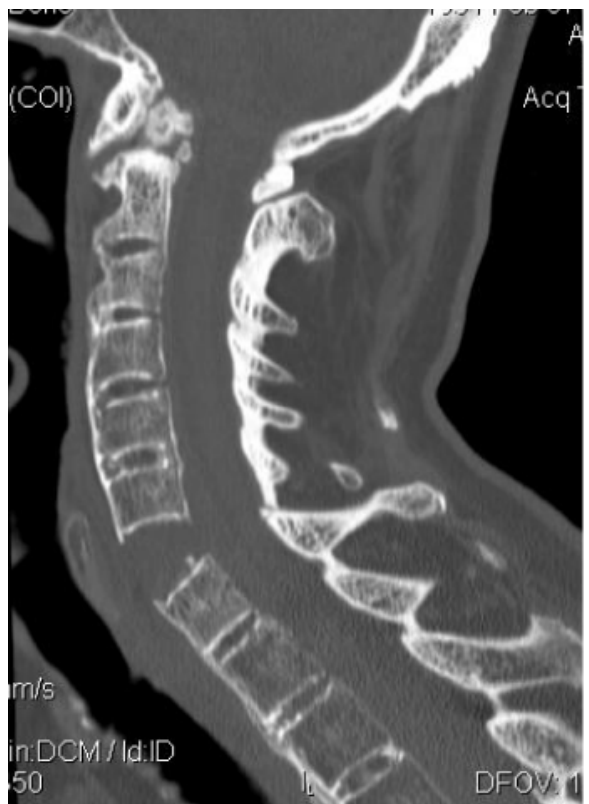

FIG. 2. Sagittal reformatted CT scan revealing a C6-7 interdiscal fracture sustained after a fall from standing height. Note the highly displaced nature of the fracture and the involvement of both the anterior and posterior elements of the vertebral column.

the general population. Using Finnish national prevalence data, Alaranta et al. ${ }^{1}$ more recently determined that the incidence of SCI in patients with AS was 11.4 times $>$ that in the population at large. A higher incidence of cervical SCI has also been noted in the population with AS, accounting for up to $84 \%$ of all cord injuries, ${ }^{1}$ in comparison to a $55 \%$ incidence of cervical SCI in the general spinal cord-injured population..$^{36}$ The incidence of complete SCI also appears to be higher in patients with $\mathrm{AS}^{1,12,19,30,39}$ than in the general population. Patients with AS who sustain an SCI are older than the general spinal cord-injured population, with a mean age from 55 to 61 years in various series ${ }^{1,5,34,39} \mathrm{com}$ pared with a mean age of 37 in the spinal cord-injured population at large. ${ }^{25}$

The higher incidence of SCI in AS is, of course, directly correlated with the increased incidence of vertebral column fractures in patients with AS. As detailed earlier, there are numerous reasons for the increased incidence of fracture in the axial skeleton of patients with AS. Furthermore, beyond the direct consequence of mechanical compression related to vertebral fracture, there are numerous other factors that contribute to the observed increased incidence of $\mathrm{SCI}$ in patients with AS.

For instance, vertebral fractures are often initially missed in patients with AS (Fig. 3). This unfortunate occurrence is likely to be multifactorial in its origin. First, as discussed earlier, in patients with AS, vertebral fractures often develop in the background of trivial trauma, and thus the physician's index of suspicion may not be appropriately raised. Second, patients with AS commonly have both acute and chronic back pain, and the appropriate fracture diagnosis can be overlooked by attributing axial pain to normal disease activity. Third, given the highly abnormal structure of the vertebral column in patients with AS, spinal fracture diagnosis can be difficult on the basis of plain radiographs
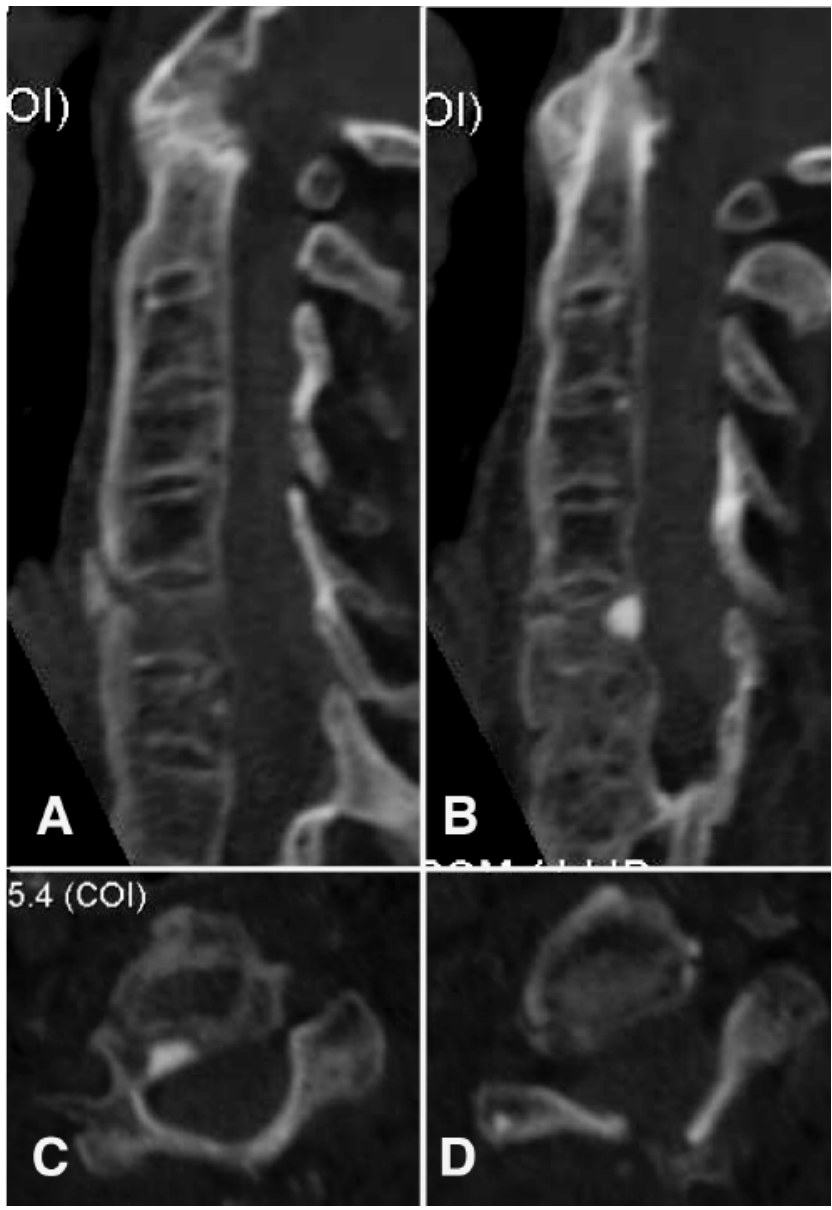

FIG. 3. Sagittal reformatted (upper) and axial (lower) CT scans showing a C5-6 interdiscal fracture. This patient initially presented to another hospital with neck pain but no neurological symptoms after falling while intoxicated. Plain radiographs were interpreted as normal, and the patient was discharged. He returned 3 days later with progressive weakness in all 4 limbs.

alone. This possibility is further confounded by the fact that many AS-related spinal fractures are located in the lower cervical spine and are poorly visualized on radiographs, which are difficult to interpret due to projection of the shoulder girdle. Accordingly, CT should be used to image the spinal column whenever a patient with AS presents with symptoms of new neck or back pain, no matter how minor or trivial the reported mechanism of injury.

Even when fractures are appropriately diagnosed, spinal column fractures in patients with AS are notoriously unstable. This high level of instability is directly related to the AS disease process. Ankylosing spondylitis promotes the ossification of spinal ligaments, which then also fracture as part of the injury pattern, further decreasing the structural support available to the spinal column. This instability often results in highly distracted vertebral column injuries (Fig. 2). The increased severity of osseous injury correlates with an increased incidence of SCI. Moreover, the greater instability significantly increases the risk of iatrogenic SCI during patient transportation and maneuvers aimed at reducing fracture dislocation. Accordingly, great care should be used whenever patients with AS and spinal frac- 


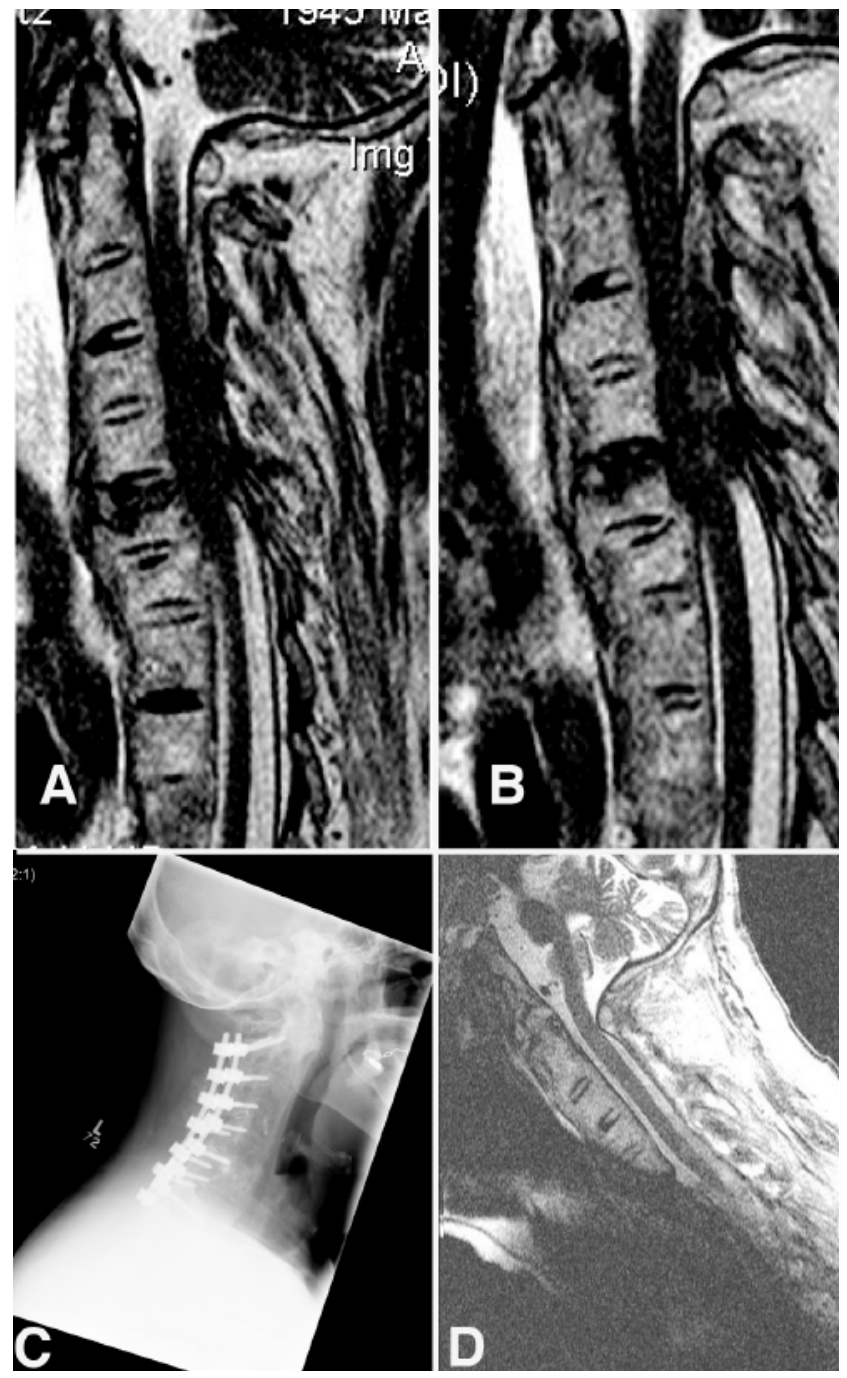

Fig. 4. Sagittal T2-weighted MR images (A and B) obtained in the same patient featured in Fig. 3, demonstrating a heterogeneous dorsally located epidural collection extending from C-3 to C-7, which represents a spinal epidural hematoma. This patient underwent emergent posterior cervical decompression and instrumented fusion from $\mathrm{C}-2$ to $\mathrm{T}-1$. Postoperative lateral cervical spine radiograph (C) demonstrating the instrumentation construct. Sagittal T2-weighted MR image (D) revealing adequate decompression of the cervical spinal cord.

tures are moved, and reduction maneuvers, if necessary, should be performed only by experienced individuals.

The incidence of SCI is also increased in the setting of AS because of the greater incidence of spinal epidural hematoma (Fig. 4) following vertebral fracture in these patients, although this finding is not universal. ${ }^{15}$ Spinal epidural hematoma occurs due to bleeding from the epidural venous plexus and/or diploë of the pathological bone. Posttraumatic spinal epidural hematoma occurs with an incidence of 10-50\% $\%^{19,20,34}$ and often has devastating neurological consequences if not recognized and treated emergently.

\section{AS and SCI: Clinical Management}

Spinal cord injury can be viewed as a two-phase process in which the sum total of neurological injury results from both primary and secondary injury mechanisms (recently reviewed by Baptise and Fehlings ${ }^{7}$ ). The primary injury consists of the initial mechanical injury that occurs immediately following the traumatic event as a result of energy propagation from the deformed vertebral column to the spinal cord. Secondary injury begins in the minutes to hours following the primary injury and encompasses a complex cascade of cellular and biochemical processes. Secondary injury leads to neuronal and glial injury and death in a delayed fashion. These secondary mechanisms include vascular changes that promote ischemia, hemorrhage, and impaired autoregulation; ionic fluctuations that result in a loss of neuronal membrane potential; glutamatergic excitotoxicity; free radical production and lipid peroxidation; and the initiation of a robust inflammatory response.

Whereas cell death following the primary mechanical injury is almost exclusively necrotic, secondary injury events trigger a continuum of cell death that ranges from necrosis to apoptotic cell death. Together, these complex and interrelated secondary injury mechanisms promote a delayed cell death process in the spinal cord that ultimately worsens outcome after SCI. ${ }^{7,36,38}$ Because it occurs in a delayed fashion, secondary injury is a potential therapeutic target, and treatment strategies that can successfully limit secondary injury would potentially limit cell death and neurological deficit after SCI. Unfortunately, current attempts to minimize secondary injury have met with limited success, ${ }^{7}$ and the only clinical option in common practice, methylprednisolone administration, ${ }^{8}$ has limited efficacy at best.

Thus, until novel efficacious neuroprotective agents become available, the main focus of treatment of SCI in the acute phase consists of measures that aim to minimize secondary injury by providing the acutely injured spinal cord with adequate vascular perfusion and oxygenation. In this sense, the central tenets of acute SCI management are the same in both the injured patient with AS and the spinal cord-injured population at large.

The management of acute SCI should occur in an intensive care unit setting where monitoring allows early detection of hemodynamic instability, cardiac rate and rhythm disturbances, respiratory dysfunction, and hypoxemia. Treatment of acute SCI in the intensive care unit has been shown to improve neurological outcome. ${ }^{3}$ Specifically, blood pressure should be adjusted to provide a mean arterial pressure $\geq 90 \mathrm{~mm} \mathrm{Hg}$ for at least the first 48 hours postinjury and $\geq 85 \mathrm{~mm} \mathrm{Hg}$ for the 1st week postinjury. Judicious monitoring of oxygenation should also be instituted and any, even transient, hypoxia should be avoided. Despite the controversy surrounding its limited efficacy and marginal risk-benefit ratio, ${ }^{24}$ the administration of methylprednisolone remains a clinical option. ${ }^{4}$ Spinal cord-injured patients should also be supported with early adequate nutrition, and aggressive prophylaxis against deep vein thrombosis and thromboembolism should be instituted. As a minimum, low-molecular-weight heparin and compression stockings are recommended. ${ }^{2}$ Careful attention to the avoidance of decubitus ulcer formation is mandatory, as is early and aggressive treatment of infectious complications such as pneumonias and genitourinary tract infections. 


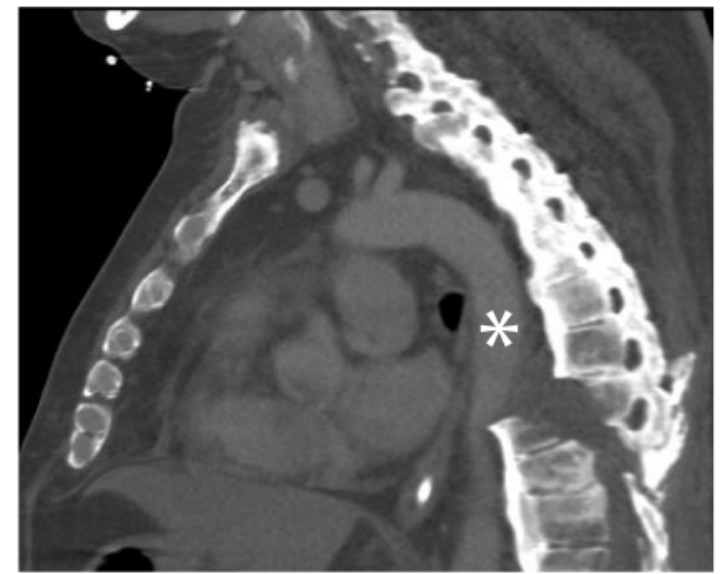

FIG. 5. Sagittal reformatted CT scan showing a highly displaced thoracic fracture. Asterisk indicates apposition of the caudal fracture fragment on the thoracic aorta.

\section{Special Considerations in the Management of SCI in AS}

As discussed earlier, spinal cord-injured patients with AS are older than the general spinal cord-injured population. In accordance with this increased age, patients with AS and SCI often have additional medical comorbidities and a poorer general level of health, independent of the AS, compared with the general spinal cord-injured patient population. Because an advanced age ${ }^{16}$ and medical comorbidities ${ }^{27}$ are both factors that worsen clinical outcome and increase the chance of death after SCI, patients with AS as a group have a higher risk of such outcomes after SCI.

Whereas the major effects of spondyloarthropathies in general, and AS in particular, are related to the axial skeleton and, to a lesser extent, the peripheral joints, ${ }^{10}$ extraarticular manifestations can be present and greatly complicate patient care following acute SCI. Uveitis and inflammatory bowel disease are the most common extraarticular features, but cardiac, pulmonary, and renal involvements are possible as well. Renal function can be impaired due to chronic nonsteroidal antiinflammatory use, glomerulonephritis, or amyloid nephropathy. ${ }^{37,42}$ Cardiac complications in patients with AS are related to conduction abnormalities and valvular heart disease. ${ }^{23,28}$ Recent evidence also suggests that atherosclerotic complications directly related to impaired endothelial function in the spondyloarthropathies may be at least partly causative. ${ }^{22}$ Beyond direct cardiac effects, aortitis is a well-described manifestation of AS and can be significant, especially in the setting of displaced thoracolumbar fractures lying adjacent to the aorta (Fig. 5). In this context, reduction maneuvers have the potential to cause injury to the diseased and weakened aorta. ${ }^{17,29}$

Pulmonary function can also be impaired due to pulmonary fibrosis, interstitial lung disease, pleural thickening, and chronic pleural effusions ${ }^{33}$ many of which are clinically silent until late in the disease process or until events such as SCI. Decreased aerobic capacity and poor pulmonary function ${ }^{13}$ are common in the patient with AS and appear to be directly related to deconditioning. Note that deconditioning occurs because of the effects of spinal ky- phosis and peripheral arthritis, which make mobility and activity increasingly difficult. ${ }^{13}$

One of the biggest factors that contributes to the morbidity and death associated with SCI in patients with AS is the decreased chest wall expansion, a central feature of AS (Table 1). ${ }^{40}$ This decrement occurs because of progressive rib immobility through syndesmophyte formation at the rib articulation with the axial skeleton and is exacerbated by the progressive thoracic kyphosis that accompanies advancing AS. Accordingly, pulmonary complications in the form of pneumonias and empyemas following SCI in patients with AS are very high and account for a large proportion of acute-phase deaths, ${ }^{39}$ but also greatly contribute to deaths occurring in the months and years after SCI.

The sum total of these added systemic maladies in the patient with AS and the same susceptibility to other complications of SCI (for example, pulmonary embolism and sepsis from urinary or decubitus ulceration sources) greatly increases the mortality rates in patients with AS and SCI. The mortality rates for patients with AS and SCI range from 35 to $50 \%$ in various series, ${ }^{19,30,34,39}$ compared with rates of $4-16 \%$ for the general population of spinal cordinjured patients. ${ }^{36}$

\section{Ankylosing Spondylitis and SCI: Prevention}

Given the high incidence of SCI and the increased morbidity and mortality rates in patients with AS who suffer an SCI, it is critical that these patients be actively engaged in primary prevention strategies to avoid this devastating complication of their disease process. Patients with AS should be encouraged to install activity aids such as handrails beside all staircases and within bathrooms, to use night lights in bedrooms and bathrooms, and to avoid loose area rugs that present a tripping risk. ${ }^{12,32}$ Excessive use of alcohol should be avoided, as should all contact sports or other high-impact physical activities. ${ }^{1}$ Seat belts should be worn at all times while driving, and car seat headrests should be used liberally. Clearly, the trade-off in terms of restricting certain aspects of daily living far outweighs the devastating morbidity and death that accompany SCI in patients with AS.

\section{Conclusions}

In summary, patients with AS have an increased rate of SCI because of their increased incidence of vertebral fractures. Moreover, they more commonly incur cervical SCIs and more frequently sustain complete injuries than the population at large. These factors combined with a highly unstable spine that is predisposed to highly distracted injuries and spinal epidural hematoma formation further increase the severity of SCI in this population. The management of SCI in the population with AS is further complicated by an advanced patient age and the presence of multiple medical comorbidities. The result is very high mortality rates following SCI. To successfully manage SCI in this complex patient population, the neurosurgeon must be cognizant of all facets of this disease process to deftly avoid complications and thus provide these patients with the best possible chance of survival. Primary prevention strategies are also paramount and provide the best means of avoiding SCI in this susceptible population. 


\section{References}

1. Alaranta H, Luoto S, Konttinen YT: Traumatic spinal cord injury as a complication to ankylosing spondylitis. An extended report. Clin Exp Rheumatol 20:66-68, 2002

2. Anonymous: Deep venous thrombosis and thromboembolism in patients with cervical spinal cord injuries. Neurosurgery 50 (3 Suppl): S73-S80, 2002

3. Anonymous: Management of acute spinal cord injuries in an intensive care unit or other monitored setting. Neurosurgery 50 (3 Suppl): S51-S57, 2002

4. Anonymous: Pharmacological therapy after acute cervical spinal cord injury. Neurosurgery 50 (3 Suppl): S63-S72, 2002

5. Apple DF Jr, Anson C: Spinal cord injury occurring in patients with ankylosing spondylitis: a multicenter study. Orthopedics 18:1005-1011, 1995

6. Aufdermaur M: Pathogenesis of square bodies in ankylosing spondylitis. Ann Rheum Dis 48:628-631, 1989

7. Baptiste DC, Fehlings MG: Pharmacological approaches to repair the injured spinal cord. J Neurotrauma 23:318-334, 2006

8. Bracken MB, Shepard MJ, Collins WF, Holford TR, Young W, Baskin DS, et al: A randomized, controlled trial of methylprednisolone or naloxone in the treatment of acute spinal-cord injury. Results of the Second National Acute Spinal Cord Injury Study. N Engl J Med 322:1405-1411, 1990

9. Braun J, Bollow M, Remlinger G, Eggens U, Rudwaleit M, Distler A, et al: Prevalence of spondylarthropathies in HLA-B27 positive and negative blood donors. Arthritis Rheum 41:58-67, 1998

10. Braun J, Sieper J: Ankylosing spondylitis. Lancet 369:13791390, 2007

11. Brewerton DA, Hart FD, Nicholls A, Caffrey M, James DC, Sturrock RD: Ankylosing spondylitis and HL-A 27. Lancet 1: 904-907, 1973

12. Broom MJ, Raycroft JF: Complications of fractures of the cervical spine in ankylosing spondylitis. Spine 13:763-766, 1988

13. Carter R, Riantawan P, Banham SW, Sturrock RD: An investigation of factors limiting aerobic capacity in patients with ankylosing spondylitis. Respir Med 93:700-708, 1999

14. Cooper C, Carbone L, Michet CJ, Atkinson EJ, O'Fallon WM, Melton LJ III: Fracture risk in patients with ankylosing spondylitis: a population based study. J Rheumatol 21:1877-1882, 1994

15. Einsiedel T, Schmelz A, Arand M, Wilke HJ, Gebhard F, Hartwig $\mathrm{E}$, et al: Injuries of the cervical spine in patients with ankylosing spondylitis: experience at two trauma centers. J Neurosurg Spine 5:33-45, 2006

16. Fassett DR, Harrop JS, Maltenfort M, Jeyamohan SB, Ratliff JD, Anderson DG, et al: Mortality rates in geriatric patients with spinal cord injuries. J Neurosurg Spine 7:277-281, 2007

17. Fazl M, Bilbao JM, Hudson AR: Laceration of the aorta complicating spinal fracture in ankylosing spondylitis. Neurosurgery 8:732-734, 1981

18. Feldtkeller E, Khan MA, van der Heijde D, van der Linden S, Braun J: Age at disease onset and diagnosis delay in HLA-B27 negative vs. positive patients with ankylosing spondylitis. Rheumatol Int 23:61-66, 2003

19. Foo D, Sarkarati M, Marcelino V: Cervical spinal cord injury complicating ankylosing spondylitis. Paraplegia 23:358-363, 1985

20. Garza-Mercado R: Traumatic extradural hematoma of the cervical spine. Neurosurgery 24:410-414, 1989

21. Geusens P, Vosse D, van der Linden S: Osteoporosis and vertebral fractures in ankylosing spondylitis. Curr Opin Rheumatol 19: 335-339, 2007

22. Han C, Robinson DW Jr, Hackett MV, Paramore LC, Fraeman $\mathrm{KH}$, Bala MV: Cardiovascular disease and risk factors in patients with rheumatoid arthritis, psoriatic arthritis, and ankylosing spondylitis. J Rheumatol 33:2167-2172, 2006

23. Heeneman S, Daemen MJ: Cardiovascular risks in spondyloarthritides. Curr Opin Rheumatol 19:358-362, 2007
24. Hurlbert RJ: Methylprednisolone for acute spinal cord injury: an inappropriate standard of care. J Neurosurg 93 (1 Suppl):1-7, 2000

25. Jackson AB, Dijkers M, Devivo MJ, Poczatek RB: A demographic profile of new traumatic spinal cord injuries: change and stability over 30 years. Arch Phys Med Rehabil 85:1740-1748, 2004

26. Karberg K, Zochling J, Sieper J, Felsenberg D, Braun J: Bone loss is detected more frequently in patients with ankylosing spondylitis with syndesmophytes. J Rheumatol 32:1290-1298, 2005

27. Krassioukov AV, Furlan JC, Fehlings MG: Medical co-morbidities, secondary complications, and mortality in elderly with acute spinal cord injury. J Neurotrauma 20:391-399, 2003

28. Lautermann D, Braun J: Ankylosing spondylitis-cardiac manifestations. Clin Exp Rheumatol 20 (6 Suppl): S11-S15, 2002

29. Lifshutz J, Lidar Z, Maiman D: Thoracic aortic pseudoaneurysm after spine trauma in ankylosing spondylitis. Case report. J Neurosurg Spine 2:218-221, 2005

30. Murray GC, Persellin RH: Cervical fracture complicating ankylosing spondylitis: a report of eight cases and review of the literature. Am J Med 70:1033-1041, 1981

31. Olerud C, Frost A, Bring J: Spinal fractures in patients with ankylosing spondylitis. Eur Spine J 5:51-55, 1996

32. Pedersen W, Clausen S, Kriegbaum NJ: Spinal lesions in patients with ankylosing spondylitis. Scand J Rheumatol 16:381-382, 1987

33. Quismorio FP Jr: Pulmonary involvement in ankylosing spondylitis. Curr Opin Pulm Med 12:342-345, 2006

34. Rowed DW: Management of cervical spinal cord injury in ankylosing spondylitis: the intervertebral disc as a cause of cord compression. J Neurosurg 77:241-246, 1992

35. Rudwaleit M, Metter A, Listing J, Sieper J, Braun J: Inflammatory back pain in ankylosing spondylitis: a reassessment of the clinical history for application as classification and diagnostic criteria. Arthritis Rheum 54:569-578, 2006

36. Sekhon LH, Fehlings MG: Epidemiology, demographics, and pathophysiology of acute spinal cord injury. Spine 26 (24 Suppl): S2-S12, 2001

37. Strobel ES, Fritschka E: Renal diseases in ankylosing spondylitis: review of the literature illustrated by case reports. Clin Rheumatol 17:524-530, 1998

38. Tator CH, Fehlings MG: Review of the secondary injury theory of acute spinal cord trauma with emphasis on vascular mechanisms. J Neurosurg 75:15-26, 1991

39. Ticó N, Ramon S, Garcia-Ortun F, Ramirez L, Castelló T, GarciaFernández L, et al: Traumatic spinal cord injury complicating ankylosing spondylitis. Spinal Cord 36:349-352, 1998

40. van der Linden S, Valkenburg HA, Cats A: Evaluation of diagnostic criteria for ankylosing spondylitis. A proposal for modification of the New York criteria. Arthritis Rheum 27:361-368, 1984

41. van der Linden SM, Valkenburg HA, de Jongh BM, Cats A: The risk of developing ankylosing spondylitis in HLA-B27 positive individuals. A comparison of relatives of spondylitis patients with the general population. Arthritis Rheum 27:241-249, 1984

42. Vilar MJ, Cury SE, Ferraz MB, Sesso R, Atra E: Renal abnormalities in ankylosing spondylitis. Scand J Rheumatol 26:19-23, 1997

43. Will R, Palmer R, Bhalla AK, Ring F, Calin A: Osteoporosis in early ankylosing spondylitis: a primary pathological event? Lancet 2:1483-1485, 1989

Manuscript submitted October 15, 2007.

Accepted October 29, 2007.

Address correspondence to: Michael G. Fehlings, M.D., Ph.D., F.R.C.S.C., Division of Neurosurgery, Toronto Western Hospital, 4W449-399 Bathurst Street, Toronto, Ontario, Canada, M5T 2S8. email: Michael.Fehlings@uhn.on.ca. 